\title{
8. Sharing the responsibility of dealing with climate change: Interpreting the principle of common but differentiated responsibilities
}

\author{
Dan Weijers, David Eng, and Ramon Das
}

\section{Introduction}

According to the 2007 Intergovernmental Panel on Climate Change report, unless global collective action on climate change can be achieved, the major threats posed by a rapidly changing climate are likely to have catastrophic effects for all life on Earth (IPCC 2007). Despite the fact all major governments have acknowledged the causal role of anthropogenic emissions in producing rapid global warming, ${ }^{1}$ little action has yet been taken to reduce such emissions.

The best hope for reaching an effective international agreement on climate change is to base it on the widely agreed upon principle of common but differentiated responsibilities (CBDR), Principle 7 of the Rio Declaration on Environment and Development. This principle captures the international consensus that the ongoing responsibility to protect the global commons is to be shared, though not necessarily evenly. In particular, the principle of CBDR notes that developed states bear a greater responsibility to address climate change because of the pressure they have put on the global environment and their financial and technological ability to take action (Rio Declaration on Environment and Development 1992). ${ }^{2}$ Unfortunately, serious disagreements remain about how the principle of CBDR is to be interpreted. At bottom, these interpretive disagreements are about justice: what is the most just way to decide what should be done about rapid climate change and who should do it? Insofar as this question hinges on matters of justice, philosophers have an important

\footnotetext{
1 United Nations Department of Public Information (1997).

2 Principle 7 of the Rio Declaration on Environment and Development provides the first formulation of the principle of CBDR, 'In view of the different contributions to global environmental degradation, States have common but differentiated responsibilities. The developed countries acknowledge the responsibility that they bear in the international pursuit of sustainable development in view of the pressures their societies place on the global environment and of the technologies and financial resources they command' (UNFCCC 1992).
} 
role to play in answering this important question. This chapter is a contribution to the ongoing philosophical debate about how the principle of CBDR can be interpreted in a way that is both fair and amenable to the formation of policy.

Within the existing literature on how to fairly divide the responsibilities of dealing with climate change, several principles of justice have emerged as the main contenders. ${ }^{3}$ As it turns out, the only current agreement on these principles of justice is that, considered individually, none distributes responsibilities in a way that is fair to all relevant parties (Page 2008). This has encouraged recent attempts to solve this problem by combining the main principles of justice into a hybrid account. The goal is to create a hybrid account that considers all of the main morally relevant considerations and distributes the responsibilities of dealing with climate change in a way that is fair to all parties and amenable to translation into policy.

In this chapter we follow the general approach just described. We first discuss the main principles of justice and note the standard objections to them, which we believe necessitate a hybrid approach. The hybrid account we defend is primarily based on the distributive principle of sufficientarianism, which we interpret as the idea that each country should have the means to provide a minimally decent quality of life for each of its citizens. We argue that sufficientarian considerations give good reason to think that what we call the 'ability to pay objection' should be taken much more seriously in this debate. Following this, our account emphasises what we believe are the two most important moral desiderata in any attempt to distribute responsibility for dealing with climate change: the ability to mitigate the problem and the making of culpable contributions to the problem. After noting that our proposal includes enough detail to be a useful start for policy makers, we defend our account against some potential objections.

\section{Polluter pays principle}

The polluter pays principle (PPP) identifies the parties who caused the pollution and apportions responsibility for paying the costs of dealing with climate change among those parties. Arguably, the PPP is the most intuitive way of thinking about the ethics of climate change. It is based on the widely shared idea that those who cause harm to others should be morally responsible for remedying that harm. As such, the PPP has the ability to provide the appropriate incentive to prevent polluting by directly linking moral responsibility, and the resulting accountability, to the kinds of actions that should be discouraged.

3 See, for example, Singer (2008), Caney (2005), Shue (1999), Neumayer (2000), Gardiner (2004), and Page (1999, 2008). 
The 'polluting' to which the PPP refers should be taken to mean the emitting of greenhouse gases above some agreed upon quota. The quotas agreed upon in the Kyoto Protocol are all self-imposed and based on a reduction of their absolute per capita or per gross national product emissions relative to some past point in time. ${ }^{4}$ These arbitrary quotas are patently unfair because they fail to acknowledge that there is no good moral reason for any distribution of a common global good, like the atmosphere, other than an equal share for everyone (Singer 2008, p. 671). There is a much fairer method of creating a quota (and one that would do more to reduce the likely catastrophic effects of climate change). This method would see the annual amount of total emissions considered safe by current United Nations Framework Convention on Climate Change (UNFCCC) estimates to be distributed to states based on their near-future population trajectory as compiled by the United Nations. ${ }^{5}$ If this approach were adopted, then the per capita aspect of this method would plausibly result in current and future people receiving their fair share of the atmosphere. The use of near-future population trajectories instead of actual populations is meant to eliminate perverse incentives for population control.

The PPP fares well when applied to current and future polluting. However, when the PPP is applied to historical emitting a problem arises from the fact past polluters, for the most part, were not aware that their actions would have harmful consequences. This fact suggests two versions of the PPP. One version is an exacting version: the full liability PPP assigns moral responsibility to agents to redress all of the relevant harms they cause even when they are unaware their actions would lead to such harm. The other version is a weaker version: the conditional liability PPP (CPPP) assigns moral responsibility only to those who knowingly pollute or who should have known that their greenhouse gas emitting was likely to cause harm. We refer to such polluting as culpable polluting. Culpable polluting is to be distinguished from non-culpable polluting on the basis of whether the polluter can reasonably be held to have known that their polluting was likely to cause harm. We believe this distinction is morally significant, so adopt a version of the CPPP in our hybrid account.

Applying the CPPP to the current climate change debate requires a method to discern who can reasonably be held to have known that their polluting was likely to cause harm. We conservatively recommend taking 1992 (when the Rio Declaration on Environment and Development was signed) as the date past

4 Singer (2008 p. 671), references Claussen and McNeilly (1998) and says the targets agreed on at Kyoto 'were arrived at through negotiations with government leaders, and they were not based on any general principles of fairness, nor much else that can be defended on any terms other than the need to get an agreement'.

5 However, as Reisinger and Larsen (in this volume) argue, more thought needs to be given to what total amount of atmospheric greenhouse gas emissions is desirable because all amounts have different predicted outcomes for the various life forms on Earth. The setting of the 'safe' level of total atmospheric greenhouse gas emissions is a moral task that deserves greater attention than it has received. 
which all states should be deemed as knowing that greenhouse gas emissions over a certain level are likely to cause harm. By using 1992 as the starting date for culpable polluting, the CPPP can satisfyingly deal with the problem of nonculpable polluting. However, Page (2008, p. 570) has criticised the use of this fairly recent date as the relevant starting date because he thinks it results in 'harsh treatment for the newly industrialised populations and lax treatment of those residing in countries of transition'. To move the starting date further back would decrease Page's fairness concerns but would exacerbate the unfairness to polluters who truly were not aware of the consequences of their actions. The combination of these two concerns makes it difficult to specify a fair date after which states should be deemed as knowing that greenhouse gas emissions over a certain level are likely to cause harm. And this difficulty, in turn, creates a problem for the PPP that it cannot easily solve by itself.

The main problem for the CPPP is that it fails to designate sufficient moral responsibility to address the problem given that a large portion of the polluting was caused before 1992 (Caney 2005). A common response to this sufficiency problem has been to argue that individuals currently residing in states that are primarily responsible for climate change should be held morally responsible for polluting that was caused by the previous generations of those states. ${ }^{6}$ Closer inspection reveals that this response is unfair. Why should the mere fact someone lives in a country, whose previous citizens polluted, make them responsible for the polluting? A possible response to this intergenerational problem is to agree that current generations should have to pay only for their own polluting and not for the polluting of past generations. Although this would be a fair and consistent application of the PPP, it suffers from the same problem as the CPPP: it fails to designate enough moral responsibility to ensure adequate mitigation of and adaptation to the potentially catastrophic effects of rapid climate change.

It could be argued that the above intergenerational problem presupposes that the relevant moral agents are individuals as opposed to states. Against this, a collectivist approach to the PPP would view states as the relevant moral agents for the current climate change debate. Such an approach has initial intuitive plausibility given that any future agreement the UNFCCC reaches will distribute the responsibilities for dealing with climate change among states in the first instance. Applying this collectivist version of the PPP reveals that, because of their relatively long history of greenhouse gas emitting, the developed nations have the primary responsibility for mitigating and adapting to rapid climate

\footnotetext{
6 Applied to the current climate change debate, the full liability PPP receives the full force of this objection while the CPPP avoids it by pure luck - it just so happens that all greenhouse-gas emitting in the distant past (by previous generations) is unknowing pollution, so cannot incur responsibilities to pay for current generations. Theoretically, however, this objection applies equally to full liability PPP and CPPP. For example, imagine applying this objection to the CPPP in 100 years' time (when our distant descendants do not want to pay for our current knowingly polluting).
} 
change. These states should pay, on this collectivist version of the PPP, because they have caused, and are likely to continue to cause, harms because of the high concentrations of greenhouse gases they have released through their historic polluting. Caney (2005) has argued against a collectivist approach to the PPP on the grounds that it would be unfair to the current citizens of an historically polluting state to have to pay for damages done by their forebears. He asks, 'individuals cannot inherit debts from parents or grandparents, so why should this be any different?' (Caney 2005, p. 760). Although we agree with the intuition that innocent individuals should not have a moral responsibility to remedy harms caused by others, we do not think Caney adequately engages with the rationale of collectivist views.

As a part of a collective, an individual is usually entitled to some benefits, but those benefits come at the cost of certain responsibilities. New citizens of New Zealand, by birth or grant, are entitled to, among other things, the benefits of social welfare, a public health system, and the freedom to live in a naturally beautiful country. However, these citizens also accrue several responsibilities, including abiding by the law and paying taxes. As a rule, the responsibilities of being a part of a collective come ineluctably hand in hand with the benefits. Therefore, individuals who did not vote for the creation of the benefits that they are now enjoying, as a part of a collective, should understand that with those benefits come responsibilities and that acceptance of the benefits entails acceptance of the whole package. Therefore, while citizens of industrialised countries are innocent of historic polluting, the collective of which they are a part is not. One may decide to opt out of the collective (of both the benefits and the responsibilities), but no one is entitled to opt out of the responsibilities only. In short, one can respond to Caney's worries about the unfairness of collective versions of PPP as follows. If individuals born into rich countries can make the case that it is unfair to require them to pay for harms they did not cause, then individuals born into poor, non-polluting countries can make an even stronger case that it is unfair that they lack so many benefits enjoyed by individuals of rich countries solely because of accidents of birth.

Therefore, a collectivist PPP, which views the relevant moral agents as states, can be defended against Caney's objections. However, as we argue later, both individual and collective versions of the PPP are susceptible to a different objection, which we call the 'ability to pay objection'.

\section{Beneficiary pays principle}

According to the beneficiary pays principle (BPP), agents who benefit from historic polluting should bear the moral responsibility for dealing with the 
problems caused by that polluting. One of the advantages of the BPP is that it easily avoids the intergenerational problem, since the BPP assigns moral responsibility to those who benefit regardless of whether they caused the pollution. According to the BPP, the response to Caney's innocent complainer should be, 'we agree that you are innocent of polluting, but you have benefited from the polluting, and that is why you have the moral responsibility to deal with it'.

The strongest ethical rationale for the BPP is based on the idea of minimising the unearned inequalities that have resulted from polluting. Unearned inequalities are welfare-affecting differences between agents that have come about because of circumstances beyond the agents' control. According to this rationale, because the benefits and costs associated with historic polluting are beyond current agents' control and are unequally distributed, the fairest way to rectify this is to assign the moral responsibility to deal with the problems caused by historic polluting to the agents who have benefited from it. On this view, the more an agent has benefited from greenhouse gas emissions, the more moral responsibility they have to pay for the mitigation of and adaptation to rapid climate change. On the face of it, this creates a fair result because it minimises the number of agents who, despite never having benefited from historic polluting, would nevertheless have to pay for the costs of it. Furthermore, by apportioning the costs of polluting in this way, the BPP moves everyone closer to a fair and equitable position in regards to the overall effects of the pollution. ${ }^{7}$

\section{Ability to pay principle}

The ability to pay principle (APP) regards states' per capita production capacity (or some other measure of welfare) as the only moral consideration in sharing the responsibilities of remedying the adverse effects of climate change. The APP requires that all and only those who can afford to pay for mitigating and adapting to climate change should pay and they should pay in proportion to their ability to pay. Adoption of the APP would result in the Annex I (developed) states paying for historic greenhouse gas emissions. ${ }^{8}$ This allocation of responsibilities is in accordance with the element of the principle of CBDR that calls on developed states to bear more responsibility for dealing with climate change because they have the ability to do so.

\footnotetext{
7 Many contemporary writers have criticised the application of the BPP to historical polluting on different intergenerational grounds; namely, the non-identity problem. Although we think the BPP can be defended against the non-identity problem, we do not discuss the issue here. This is because we believe (as we argue below) that the BPP, like the PPP, is better rejected on the grounds of the ability to pay objection.

8 For a list of Annex I states, see UNFCCC (n. d.).
} 
Several ways exist to discern a state's ability to pay, but the most promising method is morally justified by the notion of sufficientarianism. Sufficientarianism is the principle of distribution that benefits and burdens should be shared in such a way that as many people as possible (including future people) have sufficient resources to achieve a certain level of well-being (Page 2007). ${ }^{9}$ A sufficientarian would argue that a government's primary moral responsibility is to ensure its citizens have a quality of life sufficient for a reasonable level of well-being. For practical purposes, a state's ability to provide this sufficient standard of living for its citizens should be measured by its per capita production because this is relatively easy to calculate and adequately reflects a state's ability to provide the goods that increase its citizens' quality of life. ${ }^{10}$ The level of production considered sufficient should be based on international agreement, but should probably be somewhere close to the threshold where per capita real income begins to make little difference to subjective well-being. ${ }^{11}$ Henceforth, we abbreviate 'sufficientarian-supported ability to pay principle' as 'APP'.

When a state has a sufficient level of production to provide this level of wellbeing for its own citizens, a sufficientarian would then argue that the state has a moral responsibility to ensure citizens of other states and future citizens of all states can also reach this level of well-being. As noted by Shue (1999, p. 542), this responsibility could be either weak or strong, where the strong version calls for positive action to assist others below the level of sufficiency and the weak version requires only that states are not interfered with in attempting to reach the level of sufficiency. For the APP, the strong version applies; the ability to pay for preventing the damage that rapid climate change is likely to cause creates a moral responsibility to do so. We propose that a state's ability to pay for helping other states deal with problems such as climate change be understood as the degree to which a state's per capita production exceeds the agreed level of sufficient per capita production. Of course, it could be the case that the government of a very wealthy state distributes its plentiful goods in

9 For more discussion of sufficientarianism, see Frankfurt (1987), Crisp (2003), Page (2008), and Shue (1992, 1999). Sufficientarianism might seem similar to egalitarianism and prioritarianism, but as elegantly discussed by Page (2007), the three views are not the same. An egalitarian views states of affairs as being increasingly just as they make individuals' well-being increasingly equal (and vice versa). A prioritarian sees changes in states of affairs as increasingly just as they improve the well-being of those increasingly worse off to begin with. A sufficientarian views states of affairs as being increasingly just as fewer people reside below a sufficient level of well-being. Therefore, in a situation of many unequally rich (but all very rich) agents, egalitarians and prioritarians would recommend redistributing the wealth, but a sufficientarian would not.

10 In the future, a state's ability to provide a sufficient quality of life might include consideration of its natural and cultural resources, such as pristine wilderness and celebrated heritage. The current difficulty quantifying the effects of such non-commercial goods on well-being prevents their inclusion in measures of sufficiency for now.

11 Of course, estimating the exact threshold for sufficient well-being is so fraught with difficulties that it is probably impossible to get right (Casal 2007, pp. 312-8; cf. Page 2008, p. 565). However, enough work has been done on this to create estimates that are reasonably well grounded to proceed with. For example, Baer et al. (2007) argue that the minimum should be US\$9,000 (in 1995 dollars). 
such a way that some or even many of its citizens are left without the resources required for a sufficiently good life. Although we do not wish to trivialise this issue, we set it aside here as a matter to be resolved between citizens and their governments. Thus, for present purposes, within-state distribution of income does not affect the objective assessment of whether a state has the ability to pay for protecting the global commons.

Using the idea of sufficientarianism as the moral justification for the APP, we can see that if the citizens of a poor state do not have a decent standard of living, then that state has no obligation to pay for helping citizens of other states. In contrast, if a rich country has the ability to provide more than a minimally decent life for its citizens, it is obliged to help pay for the prevention of harm to citizens of less fortunate states. A consequence of this sufficientarian justification for the APP is that a very poor country, such as Bhutan, could start polluting now without incurring any moral responsibility to mitigate its greenhouse gas emissions or pay to help others adapt to the rapidly changing climate. In fact, this view advocates that Bhutan's hypothetical polluting be paid for by all states that achieve above a certain level of production (and to the degree that their relative productions exceed this level). Although this consequence might seem unfair, and thereby pose a problem for the APP, it actually highlights a benefit of it. The current debate about climate change would never have come about if it were not for the potentially catastrophic consequences for humans, and the APP is designed to minimise the number of people living in appalling and thereby potentially catastrophic circumstances. The APP, as we define it here, ensures that people who are most likely to suffer as a result of rapid climate change are the central concern of any agreement on dealing with climate change. ${ }^{12}$ Focusing on those who are suffering in this way reflects the moral desire to have as few people as possible suffer from the existence of 'radical inequalities'; situations in which there is enough of some good for everyone but some parties have much more than enough and others have less than enough (Nagel 1977).

Although the APP captures one vital moral consideration, it fails to address another. The APP fails to assign fair distributions of moral responsibility in the common case of rich states with an equal ability to pay but differing greenhouse gas emissions. According to the APP, richer states' ability to pay for the costs of mitigating and adapting to climate change justifies their doing so regardless of whether they knowingly contribute to the problem. The omission of this

12 This result nicely reflects several of the principles of the Rio Declaration on Environment and Development (UNFCCC 1992). Principle 1 states, 'Human beings are at the centre of concern for sustainable development'. Principle 5 states, 'All States and all people shall cooperate in the essential task of eradicating poverty as an indispensable requirement for sustainable development, in order to decrease the disparities in standards of living and better meet the needs of the majority of the people of the world'. Principle 6 states, 'The special situation and needs of developing countries, particularly the least developed and those most environmentally vulnerable, shall be given special priority. International actions in the field of environment and development should also address the interests and needs of all countries'. 
consideration departs from the original text of the principle of CBDR, which ties developed nations' responsibilities for dealing with the costs of climate change to their greater role in producing it (as well as their greater ability to pay). More importantly, the failure to consider who knowingly created the climatechanging pollution creates unfair burdens on equally rich but non-polluting states.

\section{Ability to pay objection to the polluter pays principle and beneficiary pays principle}

Despite its own weaknesses, a sufficientarianism-based ability to pay constraint - the ability to pay objection - can be applied to the PPP and the BPP to highlight an important problem for both principles. The ability to pay objection has not been afforded much attention in the literature, especially as an objection to the BPP. ${ }^{13}$ We argue that the ability to pay objection reveals how the PPP can unfairly assign moral responsibility to some agents without the ability to pay for it and that the BPP can fail to assign moral responsibility to some agents that do have the ability to pay for it.

If the notion of sufficientarianism is taken seriously, then very poor states should focus on their primary moral responsibility, the welfare of their citizens, and not the welfare of citizens belonging to other states. However, if we take either the individualist or collective version of the PPP seriously, then we allow for the possibility that some currently polluting, but still very poor, states will be morally obliged to help much richer states deal with the deleterious effects of climate change. According to the PPP, even if a state lacks the resources to provide a minimally decent quality of life for its citizens, it must pay for any polluting that it does; this remains the case even if the polluting is the result of efforts to raise the abysmal living conditions of the state's citizens. As a practical matter, no beneficent (or even self-interested, democratic) government would voluntarily deprive its own citizens of the basic goods of life to relieve some richer people from (what is to them) a tiny burden. And, more importantly, it would be unfair to obligate such a government to do so. Imagine a state that emits greenhouse gases in an attempt to rebuild its capacity to offer basic services to its citizens after being ravaged by famine and war. Even if it is currently polluting, it would be grossly unjust to require the government of such a state to give resources badly needed by its own citizens to some international fund so other citizens (most of whom already enjoy a comfortable life) do not have to contribute as much themselves.

13 For example, Caney (2005) uses a weaker version of this objection to argue that the PPP needs to be supplemented with the APP, but he does not use it to object to the BPP. 
Another version of the ability to pay objection reveals how the BPP can also fail to assign moral responsibility to some culpable agents that do have the ability to pay for it. Imagine two states that have the same ability to pay, although one state has acquired its ability through historical non-polluting activities and the other from historical pollution-causing industrialisation. Let us further imagine that the latter state switched over to entirely renewable energy in the relatively recent past, and that none of its current citizens have ever produced any greenhouse gases. According to the BPP, the historically polluting state should bear moral responsibility for mitigating and adapting to climate change because it has benefited from greenhouse gas emitting, while the non-polluting state should bear none. It might be argued that it is fair for citizens of such nonpolluting states to bear no responsibility to deal with climate change because they have neither caused nor benefited from it. However, a comparison of these citizens with the citizens of the benefiting state reveals that both are equally innocent of polluting and both enjoy unearned benefits. In both cases, the polluting and non-polluting actions that led to the benefits were beyond the current citizen's influence, so, in both cases, the benefits the current citizens enjoy are unearned. In the same way, neither generation of citizens caused the historic polluting (or non-polluting) that may have led to the current pollution, so they are equally (totally) innocent of causing the pollution. To assign more moral responsibility to the citizens of one state because the benefits that they have just happen to have come from historical greenhouse gas emitting instead of some other non-polluting actions is clearly unfair. Why should the citizens of an historically polluting state have to pay more for their unearned benefits when they had an equal (total) lack of ability to affect how those benefits came about?

The PPP and BPP both represent what appear to be important moral considerations for the climate change debate: both polluting and benefiting from polluting create some moral responsibility to deal with the harmful consequences of that polluting. However, we have argued here that the often-neglected ability to pay objection shows us two things. First, although polluters should generally pay, in some circumstances they should not have to pay (because they lack sufficient ability to do so). As a result of this, if the PPP were used to explain the principle of CBDR by itself, then the consequent apportionment of moral responsibility to deal with climate change might be unfair. And second, having benefited from polluting (as opposed to any other historical actions of our forebears) is not an important moral consideration because the sources of our benefits are generally out of our control. This finding reveals that the plausible moral justification for the BPP - that those who benefit from polluting have more responsibility to deal with the resulting pollution - does not reflect our considered judgements about what is really important in deciding who should have to bear the responsibility to deal with climate change. 


\section{Our hybrid account}

So far, we have argued that none of the three one-dimensional principles of justice discussed in this paper is without major problems of unfairness. The most natural explanation for this is that more than one moral consideration is relevant to the issue of distributing the responsibilities of dealing with climate change. Thus, it is unsurprising that some authors have offered hybrid accounts that reflect what they believe to be the relevant combination of moral considerations for this issue (for example, Caney (2005); Page (2008)).

Our proposed hybrid account combines elements of the APP and CPPP. By combining these principles, our hybrid account fits nicely with the dual rationale behind the principle of CBDR. Specifically, it matches the only two reasons given in the principle of CBDR for why developed states should bear the lion's share of the responsibility to deal with climate change: developed states put greater pressure on the environment and they possess greater technological and financial abilities to facilitate the mitigation of and adaptation to rapid climate change. Our account bears similarities to that of Caney (2005), but it differs in specific details and, more importantly, it is justified differently. In contrast to Caney's rights-based approach, we use the distributive principle of sufficientarianism as the underlying moral justification for our inclusion of both the APP and CPPP. We consider the main potential problem of rapid climate change to be the increased numbers of people who will lead miserable lives as a result. Bearing this in mind, our hybrid account appeals to the APP to ensure those who already lack a minimally decent quality of life are not put under more pressure. For similar reasons, our hybrid account appeals to the CPPP to encourage much lower levels of emissions and, thereby, decrease the chances of catastrophic climactic changes that would plunge even more people into desperate poverty.

It is important to us that our hybrid account be useful to policy makers. Specifically, it should be useful as an aid to the fair assignment of responsibilities in current and possible future situations for both developed and developing states. To do this, first, the moral agents to which our hybrid account applies need to be states. Although applying the hybrid account directly to individuals is theoretically unproblematic, it suffers from obvious practical problems. Suffice it to say that arriving at a global agreement on climate change is difficult enough when the negotiators are hundreds of states, let alone billions of individuals.

Given that the relevant moral agents are states, we propose the following process for allocating the responsibilities of dealing with climate change. First, assess which states have the ability to pay. We propose that there should be three broad categories of ability to pay (no ability to pay, clear ability to pay, and 
unclear ability to pay) each of which corresponds to a state's ability to provide a minimally decent quality of life for its current citizens. States with no ability to pay should not be assigned any moral responsibility to deal with climate change because of their overriding responsibility to raise the standard of living of their own citizens to a sufficient level. States that have a clear ability to pay should have to pay for their own greenhouse gas emissions above their quota and their share of any remaining costs (based on how many other states are in this category and how much they exceed the lower limit of the band). States that have an unclear ability to pay should have to pay for their own greenhouse gas emissions above their quota, but they should not have to help the rich states pay to deal with any outstanding pollution. We propose that 4,000 international dollars of gross domestic product (purchasing power parity) per capita (GDP-PPP-PC) should be the upper limit of the no ability to pay band and 8,000 international dollars of GDP-PPP-PC should be the lower limit of the clear ability to pay category. ${ }^{14}$ States with an unclear ability to pay would be those with 4,000-8,000 international dollars of GDP-PPP-PC. For perspective, in 2009, the United States's GDP-PPPPC was 46,433 international dollars, China's was 6,546 international dollars, and India's was 2,932 international dollars (India's projected GDP-PPP-PC for 2014 is 4,285 international dollars). ${ }^{15}$ Although we have set these thresholds according to what we believe roughly corresponds to what it takes to provide a minimally decent quality of life, a complete justification of these suggested figures would require much more research than is available and is certainly beyond the scope of this chapter.

After assessing which states have the ability to pay, the amount of existing pollution that has been 'culpably caused' (that is, caused after 1992) by each state with a 'clear' or an 'unclear' ability to pay should be gauged. Any agent with the ability to pay for dealing with the pollution it has caused must do so in full. Any remaining pollution that needs to be dealt with must have been created by past generations, the currently very poor, or rogue non-complying states. Since neither the dead people nor the poor states have the ability to pay for dealing with this pollution and the rogue states refuse to pay, the question arises of who should have to pay for it.

It might be suggested that no one should have the moral responsibility to pay for the outstanding pollution. However, if the precautionary principle and the right to development principle from the Rio Declaration on Environment and

14 The international dollar is a hypothetical currency that has purchasing power equivalent to the US dollar at a particular time. A state's purchasing power parity-adjusted annual gross domestic product is a measure of how many standardised baskets of goods that state could afford to buy at domestic prices if its total production output for the year were in money. Indexing this measure to international dollars allows for rough but meaningful across-state and across-time comparisons of how well a state can provide the basics of life.

15 These figures are from IMF (2009). 
Development are adopted, ${ }^{16}$ it must be concluded that someone has to pay for the outstanding pollution to avoid the risk of an environmental catastrophe that could have devastating effects for billions of future people. Assuming, then, that someone should bear the responsibility to pay for dealing with the outstanding pollution, a fair method for deciding who those bearers should be is required. Appealing once again to the idea of sufficientarianism, and more specifically to the idea that states that have fulfilled their responsibility to raise their own citizens' welfare to an acceptable standard then have a responsibility to ensure that all people (including future people) can reach this level of welfare, the distribution should be on an ability to pay basis. Therefore, after those who can pay for the costs of their own polluting have done so, the remaining costs should be distributed between those who can afford to pay them (states with a 'clear' ability to pay) and apportioned based on each state's degree of ability to pay. These costs should include the cost of creating institutions to encourage and, if necessary, enforce compliance of rogue states, as Caney (2005) recommends. This method of distribution is the fairest because any other method would result in the possibility of the governments of the worst-off states in the world having to forego their primary moral concern (their citizens' welfare) for the sake of generally much wealthier people elsewhere and in the future (the ability to pay objection from above).

In practical terms, our hybrid account results in the rich states paying for their own polluting and then sharing the costs associated with both the minor amounts of polluting caused by rogue states and very poor states and the historic pollution that was unknowingly caused by previous generations. Our sufficiency-based account gives primacy to the APP over the CPPP. This results in our hybrid account deeming it morally permissible for undeveloped and developing states to knowingly pollute, but only if that pollution is likely to result in higher well-being for their citizens. Because undeveloped countries can justifiably prioritise meeting the basic needs of their citizens over the less urgent needs of future people, they can knowingly pollute on our account without incurring the moral responsibility to deal with that pollution.

If we contrast our hybrid account of APP and CPPP with those that prioritise CPPP over APP, the main difference between them is that our hybrid account goes further to eliminate radical inequalities in the essentials of life between the very rich and the very poor. On the CPPP-prioritised hybrid account, very poor states do not get to fast-track themselves to a minimally good quality

\footnotetext{
16 Principle 15 of the Rio Declaration on Environment and Development states, 'In order to protect the environment, the precautionary approach shall be widely applied by States according to their capabilities. Where there are threats of serious or irreversible damage, lack of full scientific certainty shall not be used as a reason for postponing cost-effective measures to prevent environmental degradation'. Principle 3 states: 'The right to development must be fulfilled so as to equitably meet developmental and environmental needs of present and future generations' (UNFCCC 1992).
} 
of life for their citizens through rapid industrialisation because that would entail polluting above their per capita quota for a time. Therefore, the CPPPprioritised hybrid account goes against Principle 5 of the Rio Declaration on Environment and Development, which encapsulates the global agreement to try to eradicate poverty. ${ }^{17}$ More importantly, though, denying poor states the benefits of rapid industrialisation is unfair because it robs their citizens of their chance to catch up with citizens of developed states (which were not prevented from industrialising in the past). Without the chance to rapidly industrialise, undeveloped states will remain economically insignificant and continue to be forced to draw the short straw on international trade agreements.

Furthermore, if our hybrid account is enacted, then developed states should help developing and undeveloped states adapt and develop so that they can meet the basic needs of their citizens without polluting. On our hybrid account, the wealthiest countries have the responsibility for dealing with all outstanding emissions, such as those created by states without the ability to provide a minimally good life for their citizens. Therefore, it is in their best interest to ensure that they fulfil that responsibility by giving enough technology and training to developing countries to provide a strong incentive for them to industrialise in a way that creates minimal greenhouse gas emissions. This plausible way to fulfil the moral responsibility to deal with historical emissions will help to ensure that very poor countries still get the welfare benefits of industrialisation and that few if any extra problems are created for future people.

\section{Dealing with some potential objections}

As discussed above, an implication of our hybrid account is that a very poor country could emit greenhouse gases above its per capita allowance and incur no moral responsibility to deal with the effects of that emitting. Shue (1999, p. 533) warns that, 'If whoever makes a mess receives the benefits and does not pay the costs, not only does he have no incentive to avoid making as many messes as he likes, but he is also unfair to whoever does pay the costs'. On the first point, our hybrid account allows poor states to make a mess only if it increases the well-being of their citizens. Furthermore, it encourages rich states to incentivise

17 Principle 5 of the Rio Declaration on Environment and Development states, 'All States and all people shall cooperate in the essential task of eradicating poverty as an indispensable requirement for sustainable development, in order to decrease the disparities in standards of living and better meet the needs of the majority of the people of the world'. However, Principle 2 would endorse a CPPP-APP hybrid account that prioritises CPPP over our account. Principle 2 states, 'States have, in accordance with the Charter of the United Nations and the principles of international law, the sovereign right to exploit their own resources pursuant to their own environmental and developmental policies, and the responsibility to ensure that activities within their jurisdiction or control do not cause damage to the environment of other States or of areas beyond the limits of national jurisdiction' (UNFCCC 1992). 
low pollution-causing industrialisation for the poor states through technology transfer. The stipulation that poor states are permitted to emit greenhouse gases over the per capita limit only if no other means is available to increase their well-being for a similar cost could be added to enhance both of these points. Most importantly, poor states are permitted to pollute without incurring the responsibility to pay for the resulting damage only for a limited time (until they can provide a minimally good life for their citizens). On the second point, in the situations when the rich pay for the pollution of the very poor they do so (and do so fairly) because of their moral responsibility to the people of the world who do not have access to the basics for a minimally good life. This responsibility arises because the ability to secure the goods of a minimally decent life for ourselves and for others, which the citizens of rich states have, is mainly a product of chance, not deservedness. Moreover, these inequalities have been preserved and exacerbated to the further detriment of people who happen to be born into very poor countries.

Also mentioned above, Page (2008) has criticised the use of 1992 as the year after which states should have known that greenhouse gas emissions over a certain level create standing harms. According to Page (2008, p. 570), using 1992 results in 'harsh treatment for the newly industrialised populations and lax treatment of those residing in countries of transition'. Although this creates a problem for the PPP by itself, it is not a problem for our hybrid account. On our hybrid account, newly industrialised states are likely to have a low degree of ability to pay compared with states that industrialised over 100 years ago, so they will only have the responsibility to pay for a fraction of what the more established developed states have to pay. Furthermore, if a newly industrialised state happens to be as wealthy as the states that industrialised long ago, then they should have to pay as much as the more established states because they are all lucky enough to enjoy the benefits of wealth that came to them through the actions of previous generations (which were completely outside of their control).

As for the states in transition (those that are very close to the upper limit of not having the ability to pay), our hybrid account makes it morally permissible for them to pollute in order to complete the transition. However, they will incur the moral responsibility to pay for dealing with their own pollution as soon as they reach the threshold of sufficiency (when they will have an 'unclear' ability to pay - at 4,000 international dollars of GDP-PPP-PC). With this in mind, states in transition would be better off accepting technological assistance from developed states so they can complete the transition in a low pollution-causing manner and not have to undergo a comprehensive energy-production transition when they achieve the level of production that allows them to provide a minimally good quality of life for their citizens. Therefore, on our hybrid account, states in 
transition and very poor states are assigned less responsibility than developed states, because this distribution of responsibilities will help to reduce the most important inequalities between states, namely, the unequal distribution of the basic goods for a minimally decent life.

\section{Conclusion}

In this chapter, we have argued that a hybrid of the APP and the CPPP offers the best way of interpreting the principle of CBDR. More specifically, this hybrid provides the fairest guidance for sharing the responsibilities of dealing with climate change. Although our account bears interesting similarities to others in the literature, it is distinctive in prioritising the APP over the CPPP. This prioritisation stems from a distinctive rationale as to why the hybrid account on offer here should be preferred over each of the individual principles that have been discussed in the literature. We have argued that the most important moral consideration in the debate over climate change is that each government's primary responsibility is to raise its own citizens' welfare to a sufficient level for them to have a minimally good quality of life. The most important practical implication of our hybrid account is that undeveloped and developing states can continue to pollute without incurring any moral responsibility to deal with the effects of that pollution, as that polluting is the best way to achieve the agreed upon level of welfare for their citizens. This result is grounded in the conviction that the fundamental purpose of the current climate change debate is and should be to ensure that a minimally acceptable level of welfare is and will continue to be attainable for all people.

\section{References}

Baer, P., T. Athanasiou, and S. Kartha. 2007. The Right to Development in a Climate Constrained World: The Greenhouse Development Rights Framework. Berlin: Heinrich Böll Foundation.

Caney, S. 2005. 'Cosmopolitan justice, responsibility, and global climate change.' Leiden Journal of International Law 18: 747-75.

Casal, P. 2007. 'Why sufficiency is not enough.' Ethics 117(2): 296-326.

Claussen, E., and L. McNeilly. 1998. Equity and Global Climate Change: The complex elements of global fairness. Arlington, VA: PEW Center for Global Climate Change.

Crisp, R. 2003. 'Equality, priority, and compassion.' Ethics 113(4): 745-63. 
Frankfurt, H. 1987. 'Equality as a moral ideal.' Ethics 98(1): 21-43.

Gardiner, S. M. 2004. 'Ethics and global climate change.' Ethics 114(3): 555-600.

IPCC (Intergovernmental Panel on Climate Change). 2007. Climate Change 2007: The Physical Science Basis. Contribution of Working Group I to the Fourth Assessment Report of the Intergovernmental Panel on Climate Change. Cambridge, UK: Cambridge University Press.

IMF. 2009. World Economic Outlook, October 2009: Sustaining the recovery. Washington, DC: International Monetary Fund. www.imf.org/external/ pubs/cat/longres.cfm?sk=22576.0 (accessed April 2010).

Nagel, T. 1977. 'Poverty and food: Why charity is not enough.' In P. Brown and H. Shue (eds). Food Policy: The responsibility of the United States in the life and death choices. New York: Free Press, pp. 54-62.

Neumayer, E. 2000. 'In defence of historical accountability for greenhouse gas emissions.' Ecological Economics 33: 185-92.

Page, E. 1999. 'Intergenerational justice and climate change.' Political Studies 47: 53-66.

Page, E. 2007. 'Justice between generations: Investigating a sufficientarianism approach.' Journal of Global Ethics 3(1): 3-20.

Page, E. 2008. 'Distributing the burdens of climate change.' Environmental Politics 17(4): 556-75.

Shue, H. 1992. 'The unavoidability of justice.' In A. Hurrell and B. Kingsbury (eds). The International Politics of the Environment. Oxford: Oxford University Press, pp. 373-97.

Shue, H. 1999. 'Global environment and international inequality.' International Affairs 75(3): 531-45.

Singer, P. 2008. 'One atmosphere.' In T. Brooks (ed.). The Global Justice Reader. Oxford: Blackwell, pp. 667-88. (First published in P. Singer. 2002. One World: The ethics of globalization. New Haven: Yale University Press, pp. 1450, 205-8.)

UN (United Nations) Department of Public Information. 1997. UN Conference on Environment and Development (1992). www.un.org/geninfo/bp/enviro.html (last revised 23 May 1997; accessed February 2010). 
Public Policy: Why ethics matters

UNFCCC. 1992. Report of the United Nations Conference on Environment and Development. United Nations Framework Convention on Climate Change. A/CONF.151/26 (Vol. 1). www.poptel.org.uk/nssd/otherdocuments/ Agenda21.doc (accessed February 2010).

UNFCCC. n. d. List of Annex I Parties to the Convention. United Nations Framework Convention on Climate Change. http://unfccc.int/parties_and_ observers/parties/annex_i/items/2774.php (accessed February 2010). 